\title{
A FAVELA COMO PALCO E PERSONAGEM E O DESAFIO DA NARRATIVA ALTERNATIVA'
}

\author{
Marina Henriques Coutinho ${ }^{2}$
}

O artigo apresenta o contexto da nova ordem global e os efeitos da globalização na realidade específica das favelas do Rio de Janeiro. Aponta indícios de que o modelo socioeconômico atual não caminha em direção ao bemestar das populações mais pobres do planeta, mas opta por uma perspectiva otimista que enxerga a possibilidade da emersão de narrativas alternativas capazes de oferecer às comunidades o direito de voz; tece relações entre teatro/ comunidade e reflete sobre a possibilidade do palco comunitário representar um espaço de expressão capaz de resistir ao pensamento único.

Palavras-chave: globalização, teatro e comunidade, favela.

\section{Abstract}

This article discusses the present reality of the favelas of Rio de Janeiro within the context of a new world order and the effects of globalisation and argues that the current socio-economic model does not ensure the welfare of the world's poorest populations. The article, however, presents an optimistic view which envisages the emergence of alternative-narratives capable of offering communities the right to a voice, the creation of ties between community and theatre, and considers the possibility that the community stage can represent a place for expression capable of resisting the dominant thought.

Keywords: globalization, theatre and community, favela. 


\section{Por uma outra globalização}

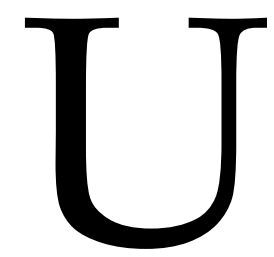

ma grande cidade de algum país em desenvolvimento é o palco para um cenário no qual as deformações e contradições do mundo capitalista globalizado ficam ainda mais evidentes. $\mathrm{O}$ processo decrescimentoeempobrecimento das grandes cidades é assunto do estudo de Mike Davis em Planeta Favela. ${ }^{3}$ Nele, o autor faz um diagnóstico mundial sobre o fenômeno da favelização, acentuada pela globalização neoliberal. Em muitas partes do mundo em desenvolvimento, as forças globais empurraram a população do campo para a cidade; a urbanização acelerada e da ausência do crescimento do emprego produziram como receita inevitável a produção em massa das favelas. Atualmente mais de um bilhão de pessoas vivem em favelas espalhadas pelas cidades do "sul do mundo". ${ }^{4}$

Mas, ainda que o cenário não seja promissor, há quem acredite que existem possibilidades de transformação. O geógrafo brasileiro Milton Santos é um deles. Em Por uma outra globalização: do pensamento único a consciência universal ${ }^{5}$, ele propõe uma tripla leitura do mundo, segundo a qual precisaríamos observá-lo por meio de três diferentes

1 Os assuntos abordados neste artigo estão aprofundados em minha tese de doutorado intitulada: $A$ favela como palco e personagem e o desafio da comunidade-sujeito, defendida em maio deste ano no Programa de Pós-graduação em Artes Cênicas da UNIRIO. Orientação: Profa. Dra. Beatriz Resende (UNIRIO); Coorientação: Profa. Dra. Márcia Pompeo Nogueira (UDESC).

2 Doutora em Artes Cênicas. Professora do Departamento de Ensino do Teatro da Universidade Federal do Estado do Rio de Janeiro - UNIRIO.

3 DAVIS, Mike. Planeta Favela. Tradução de Beatriz Medina. São Paulo: Boitempo, 2006.

40 autor observa que no relatório da UN-Habitat prevalece a definição clássica da favela, adotada oficialmente numa reunião da ONU em Nairobi, em outubro de 2002. Segundo ela, a favela é caracterizada por: "excesso de população, habitações pobres ou informais, acesso inadequado à água potável e condições sanitárias e insegurança de posse na moradia." p. 33.

5 SANTOS, Milton. Por uma outra globalização: do pensamento único a consciência universal. Rio de Janeiro: Record, 2007. perspectivas: a da globalização como fábula, como perversidade e por uma outra globalização. As perspectivas que Santos nomeia de "três diferentes mundos" a rigor compreendem três maneiras de se enxergar o mundo contemporâneo. A primeira, mais fantasiosa, apresentaria o "mundo tal como nos fazem vê-lo"; a segunda, mais realista, o "mundo como ele é"; e a terceira mais esperançosa "por uma outra globalização".

Na perspectiva da globalização como fábula, percepções enganosas estariam nos fazendo crer, por exemplo, em ideias como: "aldeia global" e "uniformidade", como se o mundo se houvesse tornado, para todos, ao alcance da mão; ou nos fazendo crer que o mercado global homogeneizou, realizou o "sonho de um mundo só", uniu o planeta, quando sabemos que na verdade ele está mais dividido do que nunca. Na perspectiva que vê o mundo como ele é, a globalização perversa, Santos afirma que:

Seja qual for o ângulo pelo qual se examinem as situações características do período atual, a realidade pode ser vista como uma fábrica de perversidade. (...) Vivemos num mundo de exclusões, agravadas pela desproteção social, apanágio do modelo neoliberal, que é, também, criador de insegurança (SANTOS, 2007, p. 59).

De acordo com Milton Santos entre os fatores constitutivos da globalização perversa encontra-se uma dupla tirania, a do dinheiro e a da informação. Segundo ele, elas representam "duas violências centrais, alicerces do sistema ideológico (...) base dos novos totalitarismos - isto é dos globaritalismos, a que estamos assistindo" (SANTOS, 2007, p. 38). Para o geógrafo, a combinação nefasta entre a tirania da informação, condicionada pelos interesses apenas de certo grupo de atores globais, alguns Estados e empresas, somada ao fetichismo do dinheiro representam as bases do pensamento que ele chamou de único e, uma ameaça a nossa existência cotidiana. 
Mesmo assim, a terceira leitura do mundo proposta por Santos - por uma outra globalização - é bastante otimista. Segundo ele, algumas pistas estariam apontando para os limites da evolução da globalização tal como ela é, perversa, e anunciando um novo período, de uma outra globalização. Santos afirma: “A pobreza é uma situação de carência, mas também de luta, um estado vivo, de vida ativa, em que a tomada de consciência é possível" (SANTOS, 2007, p. 132). Embora as grandes cidades sejam os espaços nos quais o capitalismo globalizado propicia o contágio da pobreza, é nelas também onde podem surgir alternativas.

A sociabilidade urbana cria um ambiente que favorece o estado de luta, a criação de uma política que pertence aos pobres, que é o resultado da convivência com a necessidade e com outro. Esta nova política, que Milton Santos chama de "política dos de baixo" está baseada no "cotidiano vivido por todos, pobres e não pobres, e é alimentada pela simples necessidade de continuar existindo" (SANTOS, 2007, p .133).

Se hoje a história se realiza a partir da dominação, como diria Santos, dos "vetores de cima", a perspectiva esperançosa do geógrafo enxerga a possibilidade da produção de outra história, na qual a vez será dos "vetores de baixo". A aglomeração de pessoas nos espaços das favelas pode estar produzindo uma dinâmica na qual nem sempre a busca pelo consumo, "visão limitada e unidirecionada" prevalecerá, mas que poderá ser substituída pela busca da cidadania, "elaboração de visões abrangentes e sistêmicas" (SANTOS, 2007, p. 166); que a falta de emprego e os baixos salários poderão inspirar soluções inventivas no mundo do trabalho; anunciando também um tempo em que a cultura popular ganhará mais força e que a mídia deixará de representar apenas o senso comum imposto pelo pensamento único. É neste momento, que verificamos a possibilidade da produção de um novo discurso, de "um novo grande relato". (SANTOS, 2007, p. 21)
No artigo, Contra-narrativa, ser ou não ser: esta não é a questão, ${ }^{6}$ as reflexões do professor Tim Prentki caminham na mesma direção que as de Milton Santos. Nele, Prentki discorda da perspectiva pósmoderna de que as grandes narrativas foram dissolvidas nos conflitos globais do século $X X$, para argumentar que, ao contrário, esses conflitos deram lugar: "A dominância de uma única e totalizante supernarrativa do capitalismo em sua forma corrente: o modelo neoliberal de globalização" (PRENTKI, 2009, p. 1).

Este controle não está evidente apenas nos mercados financeiros, se manifesta também nas operações das mídias globais, por meio das quais um pequeno número de atores diz à maioria o que acontece no mundo, decide o que devemos saber e pensar, como nos comportar, o que devemos consumir ou até mesmo, sentir. Prentki recorre ao educador Paulo Freire para afirmar que o que está em jogo é a nossa impossibilidade de "dar nome ao mundo", uma vez que outros estão fazendo isto por nós. De acordo com o professor, a retomada da capacidade de nomear $o$ mundo ${ }^{7}$ não estaria condicionada à criação de contra-narrativas, mas sim à produção de narrativas alternativas, essas sim capazes de perturbar a supernarrativa em vigência.

Segundo Prentki, nas narrativas alternativas, as relações são construídas na base da dignidade e não do dinheiro. Por meio de ações sociais criativas e da "autodeterminação de agrupamentos formados por relações horizontais e não verticais" (PRENTKI, 2009, p. 16) elas colaboram com a emersão de novos poderes que se expressam nas vozes dos "vetores de baixo", diria Milton Santos.

6 PRENTKI, Tim. Contra-narrativa, ser ou não ser: esta não é a questão. In: NOGUEIRA, Márcia Pompeo (org.) Teatro na Comunidade: Interações, Dilemas e Possibilidades. Florianópolis: UDESC, 2009. Anais do 10 Seminário Teatro e Comunidade: interações, dilemas e possibilidades, organizado pela Profa. Márcia Pompeo Nogueira. CEART/UDESC de 12 a 14/11 de 2008.

7 Ao se remeter ao pensamento de Paulo Freire, Prentki retoma a noção maior da "educação como prática da liberdade" que é devolver ao homem a sua responsabilidade histórica - o homem como sujeito que elabora o mundo, que emerge do lugar de mero objeto para assumir o papel de autor crítico e consciente da história. 
Assim, a despeito do mundo tal como ele é - perverso - outras narrativas estariam revelando, ainda que em doses discretas, o potencial para provocar mudanças.

\section{Cultura, arte e revanche no Rio de Janeiro}

Uma das evidências da eminência de um novo período é, na opinião de Milton Santos, a maneira como se vê revigorada a cultura popular. A vida cultural não escapa da influência que exerce a globalização sobre a nossa existência. Se por um lado observa-se a ação da cultura de massas, buscando imporse sobre a cultura popular, de outro é notório também a reação da cultura popular. Essa reação, que o geógrafo chama de "revanche" é evidente, por exemplo, nas manifestações expressivas próprias das comunidades populares do Rio de Janeiro que reinventam a música, o corpo, a fala. Essas manifestações exercem a sua qualidade de narrativas locais, e têm colocado em relevo, como observa Santos: "O cotidiano dos pobres, das minorias, dos excluídos, por meio da exaltação da vida de todos os dias" (SANTOS, 2007, p. 144).

As deformações do mundo atual favorecem, nos lugares onde elas são mais visíveis, a possibilidade da produção de uma outra história, cujos narradores não serão os mesmos da super-ideologia. São desses locais, como as favelas, de onde podem surgir as narrativas alternativas; a cultura e a arte têm se revelado cada vez mais um caminho pelo qual elas emergem; por meio delas cidadãos artistas cultivam um estado de luta capaz de contrariar a força das estruturas dominantes, e do pensamento único.

No Rio de Janeiro, a história do samba revelou compositores que cantaram a favela com a voz de quem enxerga a sua realidade "de dentro" dela. Atualmente, na mesma perspectiva, o vigor das letras e atitudes dos rapistas, a atuação das rádios comunitárias, a literatura marginal e outras manifestações "de dentro" da favela, inclusive de grupos de teatro são exemplos de estratégias de "revanche" desenvolvidas pelas comunidades para enfrentar as suas dificuldades.

As manifestações artísticas que emergem do território da favela expressam um movimento de luta diária, provam que a existência no espaço da pobreza permite o desenvolvimento de um estado de ação/reflexão sobre o seu próprio lugar e o mundo. É evidente que na contramão do discurso hegemônico, que historicamente estabeleceu uma representação negativa da favela, existe também a possibilidade da produção de um novo discurso, baseado na versão daqueles que estão "de dentro." Inúmeras ações oriundas dos espaços populares hoje no Rio de Janeiro trazem à tona narrativas locais, colocam em relevo o cotidiano das comunidades. Ao contrário de estar sujeita a uma escrita e a uma leitura de "fora para dentro", é ela mesma, a favela, quem vem abrindo brechas para apresentar o seu próprio relato - "de dentro para fora."

O novo discurso, que insurge do espaço da favela, é reforçado pela atuação de organizações que surgiram a partir da mobilização comunitária como o Grupo Teatral Nós do Morro, o Grupo Cultural AfroReggae, a Central Única das Favelas - CUFA e o Observatório das Favelas. Essas organizações encabeçam um movimento que explodiu na década de noventa. Hoje, uma complexa rede social constituída por iniciativas próprias das comunidades e por outras, implementadas por organismos externos a elas, porém dentro delas, têm ampliado o espaço para diversas formas de expressão artística, como o teatro, a música, a dança ou o audiovisual. A partir dos anos noventa, quando ocorre um verdadeiro boom do terceiro setor, fortalecendo a atuação das organizações não governamentais (ONGs) dentro das comunidades do Rio, o palco ganha um sentido quase milagroso. 
$\mathrm{Na}$ área teatral, o pioneiro grupo Nós do $\mathrm{Morro}^{8}$ tornou-se uma inspiração para diversos projetos sociais que têm descoberto o teatro como uma atividade sedutora e emocionante para a vida de crianças e adolescentes. Em quase toda comunidade carioca, difícil é não encontrar pelo menos um 'projeto' de teatro. É fato: longe dos refletores das salas de espetáculo mais sofisticadas da cidade, em quase toda favela do Rio, um grupo de teatro está em plena atividade.

Um surto de projetos implementados nas comunidades populares da cidade aposta no teatro, e também nas outras artes, como uma alternativa para a melhoria da qualidade de vida de crianças e jovens. $\mathrm{O}$ fenômeno é responsável pela disseminação de palcos em muitas favelas da cidade. Os resultados alcançados por alguns desses projetos, bem como a sua crescente divulgação nos veículos de comunicação, afirmou a ideia de que as linguagens artísticas exercem uma influência poderosa sobre crianças e adolescentes, representando um contraponto, ou um elemento estratégico para enfrentar e combater à violência, muito presente no cotidiano das comunidades. Esses projetos surgem com a preocupação de oferecer as atividades como uma alternativa às situações de perigo ou risco social.

Mesmo que algumas dessas instituições, como o Nós do Morro, tenham nascido antes da década de noventa, quando as favelas ainda não estavam tomadas pelas facções do tráfico de drogas como estão hoje, o surgimento da maioria desses projetos é consequência do agravo da negligência do Estado em relação às necessidades básicas dessas populações.

8 Fundado em 1986, na favela do Vidigal, o grupo Nós do Morro é uma referência entre as práticas teatrais desenvolvidas com moradores das comunidades no Brasil. 0 pioneirismo, a longevidade da iniciativa, bem como a repercussão de suas realizações dentro da favela do Vidigal, e também fora dela o meu interesse em investigá-lo durante o meu curso de Mestrado (Dissertação: Nós do Morro: percurso, impacto e transformação. O grupo de teatro da favela do Vidigal. PPGT/ UNIRIO, 2005. Orientador: prof. Zeca Ligièro) e também ao longo do Doutorado.

\section{O teatro pela comunidade e a chance da narrativa alternativa}

Organizações como o grupo de teatro do Vidigal, além de terem incentivado o "palco comunitário", também promoveram outra tendência que se verifica nas manifestações artísticas provenientes das comunidades. Elas elegem a própria favela como personagem principal de suas obras. Seja como tema central de peças de teatro ou nos curtas produzidos pelo cinema de "periferia", o que observamos é a ânsia de falar sobre a favela, uma explosão de vozes que querem, por meio de múltiplas possibilidades e expressões, contar a sua história, desta vez, com versão própria.

No teatro, a favela como palco $e$ personagem reflete a dinâmica de uma cena que surge a partir da comunidade, que elege a comunidade como protagonista - o teatro pela comunidade. As práticas teatrais comunitárias vêm sendo objeto de estudo de pesquisadores brasileiros e também estrangeiros. ${ }^{9}$ Márcia Pompeo Nogueira e Tim Prentki, embora assumam o uso de terminologias diferentes, definem com precisão o território dessas práticas que levam o teatro a determinados grupos, envolvendo a participação de pessoas comuns, suas histórias, lugares, desejos, prioridades e que são motivadas pelo desejo político de transformar, por meio do teatro, realidades individuais e coletivas. De acordo com Prentki, que opta pelo termo teatro aplicado ${ }^{10}$, essas ações estão inseridas em:

Um amplo leque de práticas teatrais e processos criativos que levam os participantes e as audiências além do

9 Nos últimos anos, as publicações da professora Márcia Pompeo Nogueira (UDESC) vêm contribuindo para a compreensão do teatro realizado com comunidades aqui no Brasil e também no exterior.

10 O termo teatro aplicado ainda é pouco conhecido no Brasil, embora já esteja sendo bastante utilizado no contexto internacional. Não caberia neste artigo aprofundar uma discussão sobre esta terminologia. 0 assunto está desenvolvido em minha tese de doutorado. 
teatro convencional e mainstream para o mundo de um teatro que responde a pessoas comuns, suas histórias, suas localidades e prioridades. O trabalho que acontece, quase sempre, em espaços informais, em lugares nãoteatrais, numa variedade de ambientes geográficos e sociais: escolas, rua, prisões, centros comunitários, conjuntos habitacionais, ou qualquer outro lugar que possa ser específico ou relevante aos interesses da comunidade (PRENTKI, 2009, p. 9 , trad. nossa). ${ }^{11}$

Para o autor, o teatro aplicado funciona normalmente em contextos onde a obra criada, e apresentada, tem uma comunicação e impactos específicos para os seus participantes e plateias. Os ativistas do teatro aplicado são motivados pela crença que esta arte, vivenciada pelos participantes e assistida pelas platéias, pode fazer alguma diferença na maneira "como as pessoas interagem umas com as outras e com o mundo a sua volta" (PRENTKI, 2009, p. 9). Prentki afirma que: "Existe um desejo político declarado de usar os processos de teatro a serviço de uma mudança social e comunitária" (PRENTKI, 2009. p. 9) Para definir o mesmo tipo de ação teatral, Márcia Pompeo Nogueira opta pelo uso do termo teatro em comunidades:

Trata-se de um teatro criado coletivamente, através da colaboração entre artistas e comunidades específicas. Os processos criativos têm sua origem e seu destino voltados para realidades vividas em comunidades de local ou de interesse. De um modo geral, mesmo usando terminologias diferentes, esboçase um método baseado em histórias pessoais e locais, desenvolvidas a partir de improvisação. Cada terminologia, a seu modo, guarda relações com um processo educativo entendido ou não como transformador. Do meu ponto de vista podemos, no Brasil, chamar essas práticas de Teatro em Comunidades (NOGUEIRA, 2008, p. 4).

11 As traduções do inglês presentes neste artigo foram feitas livremente por mim, com revisão de David Herman.
Nos exemplos de iniciativas de teatro pela comunidade, o processo artístico promove a emersão de uma cena que pertence e diz respeito especialmente àquelas pessoas $\mathrm{e}$ locais, caracterizando um movimento "de baixo para cima". Experiências como essas envolvem as pessoas em todo o processo de criação, buscando, por meio do teatro, criar um espaço no qual a sua cultura, voz e expressão possam se manifestar.

A favela é o lugar onde a tensão entre os vetores "de cima" e "de baixo" trava uma batalha diária. Um território atacado pela globalização neoliberal, perversa, cujos disparos privam as populações mais pobres do direito aos "bens públicos" como educação, saúde, segurança, lazer; mas um espaço de onde emergem ações criativas, movimentos capazes de reagir à situação de privação. Há mais de um século a favela faz parte do Rio de Janeiro, e durante a maior parte deste tempo ela tem sido vista como um território à parte. A ampla rede social que se formou nos últimos anos, incluindo movimentos comunitários e a participação de organismos da sociedade como um todo, tem tentado construir outra perspectiva, que enfrenta a cultura histórica de exclusão e que procura ver a cidade como menos partida e mais unificada.

Este novo projeto de cidade permite o encontro entre diferentes grupos sociais e territoriais, autoriza o trânsito da produção artística e cultural da favela por todos os circuitos, cria sociabilidades inéditas. De repente as celebridades que se tornam parceiras da juventude da periferia, os rostos da favela nas capas de revista, os empresários "responsáveis sociais", a favela na telenovela. Mas, diante desta complexa trama de transações sociais, políticas e também econômicas cabe desconfiar: em que situações a comunidade/favela é de fato sujeito, de fato favela pela favela, ou mero objeto do interesse de grupos, representantes dos "vetores de cima"?

É que a narrativa dominante cria a doença da exclusão, mas ao mesmo tempo prepara adocicados remédios paliativos. Algumas vezes seus interesses ocultos, objetivos ilusórios, criam um simulacro de transformação social; assim, as comoventes 
campanhas de doação na TV ou o reconhecimento pela mídia dos rostos da favela, ameaçam isentar a sociedade, deformada e desigual, da responsabilidade maior que são as verdadeiras mudanças estruturais, a democratização real das oportunidades. Isto não significa não reconhecer a necessidade de haver diálogo entre os mais variados atores sociais como órgãos governamentais, agências de cooperação internacional, universidades e escolas, empresas, políticos, artistas, intelectuais, organizações comunitárias, associações de moradores; mas, que se deva avaliar em que medida a favela/comunidade tem sido tratada como sujeito de seus desejos ou como objeto de interesses alheios.

O diálogo ampliado entre diversos setores da sociedade obriga uma constante negociação entre personagens que guardam entre si diferentes posições de poder. Esta é uma negociação inevitável, faz parte do convívio com a tensão entre os vetores "de cima" e "de baixo". Mas o que está em jogo nessa tensão é a seguinte pergunta: $a$ quem interessa mais o "projeto"? Até que ponto nele está assegurado a participação e autonomia da favela/comunidade? O que se faz necessário é refletir sobre quais circunstâncias favorecem à favela/ comunidade o seu verdadeiro direito de, nas palavras de Paulo Freire - nomear o mundo.

Sem dúvida, o encontro, entre variados atores sociais, tem contribuído com a criação de novas redes de sociabilidade e estimulado, nesses espaços populares e também fora deles, o surgimento de ações inovadoras. São exemplos de iniciativas com o potencial de promover a emersão de genuínas narrativas alternativas, baseadas em relações de troca, solidariedade e criatividade. A arte tem nesta proposta grande significado. Em tempos de insegurança e desengajamento, a arte, especialmente o teatro, que nesta reflexão mais nos interessa, tem o poder para criar espaços nos quais ganharão voz e representação narrativas alternativas; nele se restitui o espírito comunitário, o sentido do coletivo, o sentimento de pertencimento. $\mathrm{O}$ palco da favela pode ser uma arena na qual cidadãos se redescobrem mais críticos, menos espectadores e mais autores de seus destinos. A favela como palco e personagem pode significar a expressão legítima de uma comunidade em busca de seu desenvolvimento. Bertolt Brecht confiou ao teatro a tarefa de modificar o mundo. É com a mesma confiança, que o palco da favela pode assumir-se como um agente ativo, com o potencial de contribuir com alguma transformação; é necessário, entretanto, avaliar em que circunstâncias ele poderá verdadeiramente exercer este papel.

\section{Referências bibliográficas}

COUTINHO, Marina Henriques. A favela como palco e personagem e o desafio da comunidadesujeito. Tese de Doutorado. Programa de PósGraduação em Artes Cênicas da Universidade Federal do Estado do Rio de Janeiro. (UNIRIO). Defendida em maio de 2010. Orientadora: Profa. Dra. Beatriz Resende; Coorientadora: Profa. Dra. Márcia Pompeo Nogueira. DAVIS, Mike. Planeta Favela. Tradução de Beatriz Medina. São Paulo: Boitempo, 2006. FREIRE, Paulo. Pedagogia da Autonomia: saberes necessários à prática educativa. São Paulo: Paz e Terra, 1996.

NOGUEIRA, Márcia Pompeo. Teatro em comunidades, questões de terminologia. ANAIS do V Congresso da ABRACE, 2008. Disponível em: http://www.portalabrace. org/vcongresso/progpedagogia.html (arquivo pdf)

PRENTKI, Tim. Contra-narrativa, ser ou não ser: esta não é a questão. In: NOGUEIRA, Márcia Pompeo (org.) Teatro na Comunidade: Interações, Dilemas e Possibilidades. Anais do $1^{\circ}$. Seminário Teatro e Comunidade: interações, dilemas e possibilidades. Florianópolis: UDESC, 2009, p. 16-19.

PRENTKI, Tim; PRESTON, Sheila. The Applied Theatre reader. London and New York: Routledge, 2009.

SANTOS, Milton. Por uma outra globalização: do pensamento único a consciência universal. Rio de Janeiro: Record, 2007. 